\title{
Review on analytical studies of some pharmaceutical compounds containing heterocyclic rings: brinzolamide, timolol maleate, flumethasone pivalate, and clioquinol
}

\author{
Asmaa A. Mandour ${ }^{1 *}$, Nada Nabil², Hala E. Zaazaa ${ }^{3}$ and Mohamed Abdelkawy ${ }^{1}$
}

\begin{abstract}
Background: The heterocyclic compounds are extremely important with wide array of synthetic, pharmaceutical, and industrial applications. Heterocyclic-containing compounds have been reported for their broad spectrum of biological activities including antibacterial, antifungal, antiviral, antiprotozoal, and anthelmintic activity.

Main text: Several techniques have been used for the quantitation of heterocyclic compounds in pharmaceutical samples such as high-performance liquid chromatography (HPLC) either equipped with UV-visible or fluorescence, in addition to liquid chromatography-mass spectroscopy, UV-visible spectrophotometry, and electrochemical techniques. This article reviewed several published methods that have been applied to detect and quantify some pharmaceutical drugs containing heterocyclic compounds focusing on four drugs: brinzolamide, timolol maleate, flumethasone pivalate, and clioquinol.
\end{abstract}

Conclusion: From literature reviews, HPLC is the most widely used analytical technique for the quantitative analysis of the four selected drugs.

Keyword: Heterocyclic, Brinzolamide, Timolol maleate, Flumethasone pivalate, Clioquinol, HPLC

\section{Background}

Analytical chemistry is the study of the separation, quantification, and chemical additives identification of herbal or synthetic materials containing one or more compounds. Recently, multi-component analysis has become one of the most attractive topics for chemists. Heterocyclic compounds are the cyclic organic compounds that contain at least one hetero atom; the commonest heteroatoms are the nitrogen, oxygen, and sulfur [1], while carbocyclic compound is a cyclic organic compound that contains the

\footnotetext{
* Correspondence: asmaa.mandour@gmail.com

'Pharmaceutical Chemistry Department, Faculty of Pharmaceutical Sciences and Pharmaceutical Industries, Future University in Egypt (FUE), 90th Street, fifth settlement, New Cairo 11835, Egypt

Full list of author information is available at the end of the article
}

entire carbon atoms in ring formation. These compounds are vital and are widely utilized in several biological processes, owing to its efficacy in various diseases [2]. Biological molecules (DNA and RNA), chlorophyll, hemoglobin, and vitamins also contain heterocyclic ring [3]. There are numerous heterocyclic compounds applied in several diseases such as triazine derivatives, which are used as antimicrobial, herbicides, urinary antiseptics, and antiinflammatory agents. Benzimidazole derivatives showed antibacterial, antifungal, antiviral, and anthelmintic activities $[2,4]$. The analysis of bulk drug materials, intermediates, impurities, or even degradation products is essential. Recently, the assay techniques including titrimetry, chromatography, spectrometry, capillary electrophoresis, and electrochemical techniques have been developed. This article 
aimed to review the several published analytical techniques and their corresponding analytical methods, which have been applied for simultaneous separation of pharmaceutical drugs containing heterocyclic compounds. The forced degradation and its application for the development of stability indicating method are highlighted in this review. This presented review article focused on four heterocyclic drugs named brinzolamide, timolol maleate, flumethasone pivalate, and clioquinol.

\section{Main Text: Heterocyclic compounds Classification and general features of heterocyclic compounds}

Though heterocyclic compounds might be inorganic or organic, the majority contains at least one carbon. While atoms, which are not carbon or hydrogen, are normally referred to as heteroatoms, this is often comparable to allcarbon skeleton [1]. Heterocyclic compounds could be categorized depending on its electronic structure. The saturated heterocycles behave similar to acyclic derivatives. Therefore, piperidine and tetrahydrofuran are conventional amines and ethers, with modified steric profiles. Thus, the heterocyclic chemistry emphasizes mainly on unsaturated derivatives with unstrained five- or sixmembered rings including pyridine, thiophene, pyrrole, and furan [3]. Heterocycles as pyridine, thiophene, pyrrole, and furan being fused to benzene rings led to the development of quinoline, benzothiophene, indole, and benzofuran, respectively. However, fusion of two benzene rings developed a third large class of compounds, including acridine, dibenzothiophene, carbazole, and dibenzofuran. The unsaturated rings could be categorized based on the incorporation of the heteroatom in the conjugated system, pi system [3]. They are classified into three, four, five, and six-membered rings. The most common heterocycles are those having five- or six-membered rings and containing heteroatoms of nitrogen $(\mathrm{N})$, oxygen $(\mathrm{O})$, or sulfur $(\mathrm{S})$.

Three-membered rings: like aziridine, oxirane, and thiirane, which contain a ring of three atoms composed of carbon atoms and one nitrogen atom, oxygen or sulfur, respectively. Four-membered rings: like azetidine, oxetane, and thietane, which contain a ring of four atoms composed of three carbon atoms and one nitrogen atom, oxygen or sulfur, respectively. Five-membered rings: like pyrrole, furan, and thiophene molecules, which contain a ring of five atoms composed of four carbons and one nitrogen, oxygen, or sulfur, respectively. Six-membered rings: like pyridine and pyrimidine, which contain a ring of six atoms composed of five carbons and one nitrogen or more, respectively.

\section{Biological importance of heterocyclic compounds}

Heterocyclic compounds have many applications: they are widely used as pharmaceuticals, as agrochemicals, and as veterinary products. They also exist in medical chemistry and as constituents of numerous biomolecules including enzymes, vitamins, and other natural products and biological compounds. Moreover, they are found in some pharmaceutical preparations including antifungals, antiinflammatory, antibacterial, antioxidants, anticonvulsants, antiallergics, enzyme inhibitors, herbicides, anti-HIV, antidiabetics, anti-neoplastic, and insecticides.

Antifungal activity: Fungi are heterotrophic microorganisms that lack photosynthetic ability. The antifungals kill fungal cells through binding the cell membrane leading to formation of pores in the membrane with leakage of proteins and cations and eventually cell death [5]. Molnar et al. detected a group of dipicolinic acid derivatives; some of them have antifungal properties against Aspergillus flavus [6]. Chitra et al. produced indole 3acetic acid-based biopolymeric hydrogels, with antifungal activities [7]. Anti-inflammatory activity: The antiinflammatory agents are substances used for management or reduction of inflammatory reactions or swellings. Anti-inflammatory agents are nearly half of analgesics since they relieve pain via decreasing inflammatory reaction without affecting the central nervous system, unlike opiates [8]. Pyrimidinone and triazine derivatives also have anti-inflammatory properties [9]. Antibacterial and anthelmintic activity: Aromatic heterocyclic derivatives are incorporated in many antibiotics including $\beta$-lactam derivatives, and some chemists have synthetized several compounds and evaluated them for antibacterial activity [10]. Benzimidazole, piperazine, quinolone, piperidine, and albendazole are different heterocyclics used as anthelmintics [10]. Antioxidant activity: Antioxidant is a molecule, which suppresses oxidation of another molecule. Such compounds include thiol or ascorbic acid that could inhibit oxidation, thus preventing cell damage [11]. Anticonvulsant and antidepressant activities: Paroxetine and reboxetine are considered as antidepressants and anticonvulsants containing heterocyclic moieties in their structure. Some piperidine and pyrimidine derivatives possess the same activities as well [12]. Antiallergic activity: There are many heterocyclic compounds with anti-allergic properties, new Bis-heteroaryl hydrazines have been synthesized as effective antiallergic compounds, and such compounds possess good potency [13]. Anticancer activity: Alkylating agents are compounds that show antineoplastic activity [14]. Antiulcer activity: A series of substituted benzimidazole compounds such as omeprazole, lansoprazole, and pantoprazole have gastric antisecretary and therefore anti-ulcer activity [15].

\section{Methods of separation}

\section{Chromatographic methods}

Chromatography is used to separate, identify, and purify components of a mixture both qualitatively and 
quantitatively. Chromatographic techniques are classified into column, thin layer, and paper chromatography [16]. Separation is based on that some components of the mixture have affinity to the stationary phase higher than that to the mobile phase and vice versa. If the component has higher affinity to the mobile phase, it will pass rapidly with the mobile phase and leave the system to be eluted first. Stationary phase is composed of solid or layer of liquid adsorbed onto inert solid support. Mobile phase may be liquid or gas. If the mobile phase is liquid, it is termed as liquid chromatography, and if gas, it is known as gas chromatography [17]. There are different types of chromatography like column, paper, dye-ligand, affinity, gas, thin layer, and high-performance liquid chromatography [16, 17]. Thin layer chromatography (TLC): a liquid-solid adsorption technique, where stationary phase is solid being adsorbed onto glass plate like alumina and silica gel, while mobile phase is liquid that travels upwards through the stationary phase. The upward travelling rate is dependent on the polarity of substance, solid phase, and solvent [18]. In highperformance liquid chromatography (HPLC), the mobile phase is liquid, which passes through a column composed of a number of theoretical plates where separation is done. Paper chromatography: a liquidliquid chromatography where the mobile phase is liquid present in a developing tank and the stationary phase is a layer of cellulose (support) saturated with water. Affinity chromatography is used for purification of proteins, enzymes, nucleic acids, hormones, and antibodies [19]. Gas chromatography: a gas-liquid chromatography where the mobile phase is inert gas like $\mathrm{He}$ or $\mathrm{N}_{2}$ and the stationary phase is liquid adsorbed onto inert solid support. It is used in the separation and analysis of multicomponent mixtures such as essential oils, hydrocarbons, and solvents [20]. Column chromatography: a precursory technique used in the purification of compounds and proteins based on their hydrophobicity or polarity. The molecule mixture is separated depending on its differential partitioning between a stationary phase, which is column, and a mobile phase is a buffer or solvent passing through the column [16]. Compared to other chromatographic techniques, HPLC is more sensitive, extremely quick, qualitative, efficient, and largely automated with the ability to purify amino acids, proteins, nucleic acids, hydrocarbons, carbohydrate, and some medications such as antibiotics and corticosteroids [16]. The mobile phase passes through columns under 10-400 atmospheric pressure and with a high flow rate. HPLC separation ensures the presence of certain components including solvents, pressure pump, column, detector, and recorder. Duration of separation is controlled by a computer [21].

\section{Spectroscopic methods}

Spectroscopic methods are widely used for simultaneous determination of different mixtures of drugs without prior separation by some mathematical equations, and these were found to be simple, very rapid, and with low cost compared to LC-MS and LC-GC [22]. Absorption spectroscopy is a powerful tool for quantitative analysis of analyte since there is a relation between the concentration of analyte and amount of light absorbed [22]. Near-infrared and Raman spectroscopy have been increasingly used for real-time measurements of critical process during pharmaceutical processing, as these spectroscopic techniques allow rapid and nondestructive measurements without sample preparations [23]. They are used for quantitative analysis of multicomponent with aid of chemometric tool. Therefore, they are used as Process Analytical Technology (PAT) tool for pharmaceutical industry [24].

Spectrophotometric method is a multicomponent analysis technique where the spectra of drugs overlap, and some simultaneous equations can be done to resolve such overlapping where the concentration of each individual analyte can be determined. Spectrophotometric technique depends on the following: (a) The spectrum of the solution: since the spectroscopy is an additive technique, therefore the absorbance of the solution is the sum of the absorbance of its individual components, so the spectrum of the solution is the sum of the spectra of its separate components [25]. (b) Beer-Lambert's law must be obeyed, as $[A=a b C]$ where $A$ is the absorbance, $C$ is the concentration of analyte, $a$ is the absorptivity constant, and $b$ is the path length. There is a direct relation between $A$ and $C$, so if we construct a calibration curve, it must pass through the origin. BeerLambert's law is only applied for the diluted solutions not more than $0.01 \mathrm{M}$, as the concentration increases, deviation from linearity will occur [26]. (c) The absorbance measured is always the difference between the absorbance of the solution of interest present in the sample cell and that of the solution present in reference cell (blank) [27].

Several spectrophotometric methods were applied on pharmaceutical compounds including the following: (1) Methods based on the zero order absorption spectra: Like dual wavelength, induced dual wavelength, dual wavelength resolution technique, absorption correction method, absorbance subtraction, advanced absorbance subtraction, absorptivity factor method, area under the curve correction, compensated area under the curve, and spectrum subtraction $[22,28]$. (2) Methods based on derivative spectra: Like amplitude subtraction, modified amplitude subtraction, amplitude factor, amplitude summation method, simultaneous derivative ratio spectrophotometry, 
modified graphical method via regression equation, differential dual wavelength, differential derivative ratio, successive derivative subtraction coupled with constant multiplication, and derivative transformation $[22,29]$. (3) Methods based on subtraction of the amplitudes of ratio spectra: Ratio subtraction method, successive ratio subtraction, extended ratio subtraction method, and simultaneous ratio subtraction method [22, 28]. (4) Methods based on amplitude difference of ratio spectra: Ratio difference spectrophotometric method, constant center spectrophotometric method, constant center coupled with spectrum subtraction, constant value via amplitude difference, constant value and amplitude center method [22]. (5) Methods based on modulation of amplitudes of ratio spectra: amplitude modulation advanced amplitude modulation and induced amplitude modulation [22, 28]. (6) Methods based on computed geometrical representation: Geometrical amplitude modulation, geometrical induced amplitude modulation, and ratio $\mathrm{H}$ point standard addition method [22]. (7) Methods based on mean centering and wavelet transformation: Mean centering using geometric mean, pure component contribution algorithm, and continuous wavelet transform [22].

\section{Electrochemical methods}

Electrochemical is a technique that provides quantitative or semi-quantitative information about the analyte. Electrochemical techniques are classified into voltammetric, impedimetric, conductometric, potentiometric, and field-effect transistor-based biosensors [30]. Voltammetric biosensors: voltammetric and amperometric biosensors apply a potential to a working electrode versus a reference electrode and measure the produced current. The current arises from electrolysis via electrochemical oxidation or reduction at the working electrode [31]. Conductometric biosensors: they measure alteration in electrical conductivity of a sample solution as the composition of the solution is altered during a chemical reaction [32]. Potentiometric biosensors: they measure the potential of an electrochemical cell while drawing negligible current. They often contain an electrochemical cell with two reference electrodes able to measure the potential across an ion-selective membrane, which reacts with the charged ion of interest [31]. Field-effect transistor-based biosensors: they detect a change in the source-drain channel conductivity originating from the electric field of its environment. The electrical conductance of the channel is proportional to its carrier density, and this is readily sensed via the change in the source-drain voltage-current [33].

\section{The studied drugs (brinzolamide, timolol maleate, flumethasone pivalate, and clioquinol) \\ Chemistry and drug indications \\ First: Brinzolamide (BRZ)}

Brinzolamide is (4R)-4-(ethylamino)-2-(3-methoxypropyl)-1,1-dioxo-3,4-dihydrothieno[3,2-e] thiazine-6sulfonamide (Fig. 1a) [34]. Its molecular formula is $\mathrm{C}_{12} \mathrm{H}_{21} \mathrm{~N}_{3} \mathrm{O}_{5} \mathrm{~S}_{3}$, and the molecular weight is $383.5 \mathrm{~g} / \mathrm{mol}$. BRZ is whitish to off-white powder or crystals. It is insoluble in water but slightly soluble in alcohol and methanol. The melting point is $131{ }^{\circ} \mathrm{C}$ [35]. BRZ is a carbonic anhydrase inhibitor used for lowering the elevated intraocular pressure as in patients with ocular hypertension or open-angle glaucoma [36].

\section{Second: Timolol maleate (TM)}

Timolol maleate is (-)-1-(tert-Butylamino)-3-[(4-morpholino-1,2,5-thiadiazol-3-yl) oxy]-2-propanol maleate (1:1) (salt) (Fig. 1b) [37]. Its molecular formula is $\mathrm{C}_{13} \mathrm{H}_{24} \mathrm{~N}_{4} \mathrm{O}_{3} \mathrm{~S} \cdot \mathrm{C}_{4} \mathrm{H}_{4} \mathrm{O}_{4}$, and the molecular weight is $432.49 \mathrm{~g} / \mathrm{mol}$. It is whitish or almost whitish, odorless crystalline powder. It is soluble in water, alcohol, and methanol, sparingly soluble in chloroform and propylene glycol but insoluble in ether and cyclohexane. Its melting point is $202-203^{\circ} \mathrm{C}$ [38]. TM is a non-selective betaadrenergic blocker used as eye drops to decrease intraocular pressure for treatment of open-angle glaucoma. It is also utilized as tablets to reduce elevated blood pressure [39].

\section{Third: Flumethasone pivalate (FP)}

Flumethasone pivalate is 6a,9-difluoro-11b,17a-dihydroxy-16a-methyl-21-trimethylacetoxy1,4-pregnadiene-3, 20-dione (Fig. 1c) [40]. Its molecular formula is $\mathrm{C}_{27} \mathrm{H}_{36} \mathrm{~F}_{2} \mathrm{O}_{6}$, and molecular weight is $494.6 \mathrm{~g} / \mathrm{mol}$. FP is virtually whitish, odorless, fine crystalline powder. It is slightly soluble in methanol as well as ethanol, very slightly soluble in chloroform as well as methylene chloride, but insoluble in carbon tetrachloride and isooctane [41]. FP is a moderately potent difluorinated corticosteroid ester with anti-inflammatory, antipruritic, and vasoconstrictive activities. Its anti-inflammatory effect is concentrated at application site. Such local action causes reduction in inflammatory reaction, exudation, and pruritis [41].

\section{Fourth: Clioquinol (CL)}

Clioquinol is 5-chloro-7-iodo-8-quinolinol (Fig. 1d) [42]. The molecular formula of $\mathrm{CL}$ is $\mathrm{C}_{9} \mathrm{H}_{5} \mathrm{ClINO}$, and its molecular weight is 305.5 . CL is freely soluble in pyridine, dimethylformamide, and hot ethyl acetate; sparingly soluble in dioxane; and slightly soluble in ethanol, while water insoluble [43]. It belongs to hydroxyquinolines that suppress particular enzymes associated with DNA 
$\mathbf{a}$<smiles>CCN[C@H]1CN(CCCOC)S(=O)(=O)c2sc(S(N)(=O)=O)cc21</smiles><smiles>C[C@@H]1C[C@H]2[C@@H]3C[C@H](F)C4=CC(=O)C=C[C@]4(C)[C@]3(F)[C@@H](O)C[C@@]2(C)[C@]1(O)C(=O)COC(=O)C(C)(C)C</smiles>

b<smiles>CC(C)(C)NC[C@H](O)COc1nsnc1N1CCOCC1</smiles>

d<smiles>Oc1c(I)cc(Cl)c2cccnc12</smiles>

Fig. 1 Chemical structure of brinzolamide (BRZ) (a), timolol maleate (TM) (b), flumethasone pivalate (FP) (c), and clioquinol (CL) (d)

replication. It has antifungal and antiprotozoal activities [43].

\section{Methods and techniques of analysis Chromatographic analysis Brinzolamide and/or timolol maleate}

Surveying literature 2000-2019 revealed that many chromatographic analysis methods have been applied for the determination of brinzolamide as well as timolol maleate. HPLC is the most commonly applied chromatographic technique for the determination of brinzolamide and timolol maleate [44-57].

\section{1- High performance liquid chromatography technique (HPLC)}

Ibrahim et al. [44] introduced an HPLC method for simultaneous determination of dorzolamide, brinzolamide, and brimonidine combined with timolol. The mobile phase was acetonitrile to $0.05 \mathrm{M}$ phosphate buffer $(30: 70 \mathrm{v} / \mathrm{v})$ at $\mathrm{pH} 3.5$ and wavelength of $220 \mathrm{~nm}$ using Promosil C18 column. The linearity was $1.25-25 \mu \mathrm{g} / \mathrm{mL}$ for timolol, $4-80 \mu \mathrm{g} / \mathrm{mL}$ for dorzolamide, $5-50 \mu \mathrm{g} / \mathrm{mL}$ for brinzolamide, and $2-20 \mu \mathrm{g} / \mathrm{mL}$ for brimonidine [44]. Yet, a simple RP-HPLC method was developed by Patel et al. [45], for the simultaneous determination of brinzolamide and brimonidine in their combined dosage form. The separation was carried out by Zorbax SB C18 (250 $\mathrm{mm} \times 4.6 \mathrm{~mm} \times 2.6 \mu \mathrm{m}$ ) column and buffer (potassium phosphate, $\mathrm{pH} 3.0$ to acetonitrile $(60: 40 \mathrm{v} / \mathrm{v})$ as mobile phase. The flow rate was $1 \mathrm{~mL} / \mathrm{min}$, and the detection wavelength was $225 \mathrm{~nm}$. The linearity was $2-6 \mu \mathrm{g} / \mathrm{mL}$ for brimonidine and $10-30 \mu \mathrm{g} / \mathrm{mL}$ for brinzolamide [45]. Previously, Anusha et al. [46] showed that chromatographic separation of brinzolamide and timolol maleate was achieved by Inertsil ODS C18 column $(250 \times 4.6$ $\mathrm{mm}, 5-\mu \mathrm{m}$ particle size) with mobile phase consisting of sodium dihydrogen phosphate buffer $(0.2 \mathrm{M})$ to methanol $(70: 30 \mathrm{v} / \mathrm{v}) \mathrm{pH} 7.5$ with sodium hydroxide solution at a flow rate of $1.0 \mathrm{~mL} / \mathrm{min}$ and injection volume of $10 \mu \mathrm{L}$. The analytes were detected at $279 \mathrm{~nm}$ using by UV detector. The linearity was $0.0001-0.0018 \mathrm{mg} / \mathrm{mL}$ for brinzolamide and $0.0001-0.0023 \mathrm{mg} / \mathrm{mL}$ for timolol maleate [46]. Moreover, Shankar and Venkateshwarlu [47] developed a method for the determination of brinzolamide and timolol maleate by utilizing C18 Column (150 mm $\times$ $4.6 \mathrm{~mm}, 5 \mu \mathrm{m})$. The flow rate was $1 \mathrm{~mL} / \mathrm{min}$ while mobile phase was methanol to phosphate buffer $\mathrm{pH} 4.0$ (70: $30 \mathrm{v} / \mathrm{v})$. The detection was performed at $260 \mathrm{~nm}$. The linearity range of brinzolamide was $5-25 \mu \mathrm{g} / \mathrm{mL}$, while for timolol maleate was $20-100 \mu \mathrm{g} / \mathrm{mL}$ [47]. Hassib et al. [48] published a unique research for a LC-MS/MS method for the simultaneous determination of timolol maleate with other co-administered drugs as dorzolamide hydrochloride, brinzolamide, and brimonidine tartrate in rabbit aqueous humor utilizing eslicarbazepine as internal standard. The separation was performed with a mobile phase of $10 \mathrm{mM}$ ammonium format $\mathrm{pH} 7$ to 
methanol to acetonitrile (5:50:45 by volume). The flow rate was $0.8 \mathrm{~mL} / \mathrm{min}$ on an INERTSIL $\left(^{\circ}\right)$ C18 ODS-3 column $(150 \mathrm{~mm} \times 4.6 \mathrm{~mm}, 3.5 \mu \mathrm{m})$. The method was carried out utilizing electrospray ionization source in a positive ionization mode, and the detection was performed via multiple reaction monitoring at the succeeding transitions: $\mathrm{m} / \mathrm{z} 317.2 \rightarrow 261.0$ for timolol maleate, $\mathrm{m} / \mathrm{z} 325.1 \rightarrow 199.0$ for dorzolamide hydrochloride, $\mathrm{m} / \mathrm{z}$ $384.2 \rightarrow 281.0$ for brinzolamide, $\mathrm{m} / \mathrm{z} 292.1 \rightarrow 212.0$ for brimonidine tartrate, and $\mathrm{m} / \mathrm{z} 255.0 \rightarrow 237.0$ for internal standard. The linearity range was $50-5000 \mathrm{ng} / \mathrm{mL}$ for the entire medications [48]. Agrawal et al. [49] introduced a RP-HPLC method for the simultaneous determination of brimonidine tartrate and brinzolamide. The separation was carried out on C18 column $(250 \times 4.6$ $\mathrm{mm}, 5 \mu \mathrm{m})$, and the mobile phase was composed of methanol to $0.01 \mathrm{M}$ ammonium acetate buffer (49.5:50.5 by volume), $\mathrm{pH}$ adjusted to 3.8 . The flow rate was 1.1 $\mathrm{mL} / \mathrm{min}$, and the detection wavelength was $260 \mathrm{~nm}$. The linearity range was $0.2-1.4 \mu \mathrm{g} / \mathrm{mL}$ for brimonidine tartrate and $1-7 \mu \mathrm{g} / \mathrm{mL}$ for brinzolamide [49]. Christian et al. [50] suggested a HPLC method for the detection of brinzolamide as well as brimonidine tartrate. Using an isocratic RP-HPLC Phenomenex C18 $(5 \mu \mathrm{m}, 250 \times 4.6$ $\mathrm{mm})$ column and a mobile phase of phosphate buffer ( $\mathrm{pH}$ 6.6) to acetonitrile to methanol (45:15:40 by volume) flowed at a rate of $1.0 \mathrm{~mL} / \mathrm{min}$, and detection was achieved at $254 \mathrm{~nm}$. The linearity of the two drugs was $50-1600 \mathrm{ng} / \mathrm{mL}$ [50]. Kumari et al. [51] introduced a stability indicating RP-HPLC method for the simultaneous detection of travopost and timolol in bulk and pharmaceutical dosage forms. The separation was performed on Intersil ODS $(150 \times 4.6 \mathrm{~mm}, 5 \mu \mathrm{m})$ column, and the mobile phase was acetonitrile to buffer in the ratio of 10:90. The flow rate was $1 \mathrm{ml} / \mathrm{min}$, and the detection wavelength was $213 \mathrm{~nm}$. The linearity ranged from 12.5 to $75 \mu \mathrm{g} / \mathrm{mL}$ for timolol and 10 to $60 \mu \mathrm{g} / \mathrm{mL}$ for travopost [51]. Rizk et al. [52] developed a stability-indicating micellar liquid chromatographic (MLC) method for detecting timolol maleate in presence of its degradation products. An isocratic, rapid, and mobile phase saving the micellar LC method was developed using a Bio Basic Phenyl column $(150 \times 1.0 \mathrm{~mm}, 5-\mu \mathrm{m}$ particle size $)$, and a micellar mobile phase of $0.1 \mathrm{M}$ sodium dodecyl sulfate, $10 \%$ of 1 -propanol, and $0.1 \%$ of triethylamine in $0.035 \mathrm{M}$ ortho-phosphoric acid flowed at a rate of $0.1 \mathrm{~mL} / \mathrm{min}$. The detection wavelength was $298 \mathrm{~nm}$. The linearity was $50-2500 \mathrm{mg} / \mathrm{mL}$ for timolol [52]. Hafez et al. [53] suggested an UPLC method for the determination of brimonidine tartrate, timolol maleate, and benzalkonium chloride in eye drops. The method was carried out on Phenomenex Kinetex C18 $(50 \times 4.6 \mathrm{~mm}, 2.6 \mu \mathrm{m})$, and the mobile phase was methanol and 1-Decane sulphonic acid sodium ( $\mathrm{pH} 3.0)$. The flow rate was $0.6 \mathrm{~mL} / \mathrm{min}$ at
$50{ }^{\circ} \mathrm{C}$ in gradient manner. Detection was done at wavelength $320 \mathrm{~nm}$. The linearity was $1-100 \mu \mathrm{g} / \mathrm{mL}$ for brimonidine and $2.25-225 \mu \mathrm{g} / \mathrm{mL}$ for timolol [53]. Also, Khatun and Islam [54] described a reversed phase-HPLC (RP-HPLC) method for the simultaneous detection of brinzolamide and timolol maleate in ophthalmic formulations. The separation was carried out via Zorbax Eclipse Plus, Agilent Technology $(150 \mathrm{~mm} \times 4.6 \mathrm{~mm}$, $5 \mu \mathrm{m})$ column with a mobile phase of triethylamine phosphate buffer to acetonitrile to methanol (70:20:10 by volume). The flow rate was $1.0 \mathrm{~mL} / \mathrm{min}$, and PDA detection was at $274 \mathrm{~nm}$. The linearity was $40-140 \mu \mathrm{g} / \mathrm{mL}$ for brinzolamide and $20-70 \mu \mathrm{g} / \mathrm{mL}$ for timolol maleate [54]. Laddha et al. [55] developed a stability indicating method for timolol maleate where the separation was performed on C18 column of Kromasil $(250 \mathrm{~mm} \times 4.6$ $\mathrm{mm}, 5 \mu \mathrm{m})$, and the mobile phase was phosphate buffer to methanol $(60: 40 \mathrm{v} / \mathrm{v})$. The $\mathrm{pH}$ of buffer was maintained to 3.5 by O-phosphoric acid. The detection wavelength was $295.3 \mathrm{~nm}$. The linearity for timolol was 10 $50 \mu \mathrm{g} / \mathrm{m}$. The flow rate was $1 \mathrm{ml} / \mathrm{min}$. Timolol maleate was observed to be stable in the entire conditions except in alkaline one [55]. Elshanawane et al. [56] established a HPLC method for the determination of brimonidine tartrate and timolol maleate using BDS HYPERSIL Cyano column $(250 \times 4.6 \mathrm{~mm}, 5 \mu \mathrm{m})$ and a mobile phase formed of ammonium acetate (pH 5.0) to methanol (40: $60 \mathrm{v} / \mathrm{v})$. The flow rate was $1.5 \mathrm{~mL} / \mathrm{min}$. The detection was performed at $254.0 \mathrm{~nm}$ for brimonidine tartrate and $300.0 \mathrm{~nm}$ for timolol maleate. The linearity range was $4-$ $24 \mu \mathrm{g} / \mathrm{mL}$ and $10-60 \mu \mathrm{g} / \mathrm{mL}$ for brimonidine tartrate and timolol maleate, respectively [56]. Sharma et al. [57] developed a RP-UPLC method for the detection of dorzolamide hydrochloride as well as timolol maleate in the existence of their impurities, degradation products, and placebo. Such method utilized Waters UPLC BEH C18, $100 \times 2.1 \mathrm{~mm}, 1.7 \mu \mathrm{m}$ column, and a mixture of solvents $\mathrm{A}$ and $\mathrm{B}$ as mobile phase. Phosphate buffer $(0.04 \mathrm{M}), \mathrm{pH}$ 2.6 was utilized as buffer, where buffer $\mathrm{pH} 2.6$ represented solvent A, while Milli-Q water, methanol, and acetonitrile (2:3:6 by volume) represented solvent $\mathrm{B}$. The gradient protocol was $0 / 5,8 / 8,10 / 15,16 / 45,20 / 55,24 /$ $80,25 / 5$, and 30/5. Dorzolamide hydrochloride along with its impurities were detected at $254 \mathrm{~nm}$, while timolol maleate along with its impurities at $295 \mathrm{~nm}$. The run time was half an hour [57].

\section{2- TLC densitometry}

Salem et al. [58] established a thin layer chromatography (TLC)-densitometric method for simultaneous determination of a binary mixture of timolol and travoprost without prior separation in their bulk or dosage forms. The separation was carried out on Merck 
HPTLC aluminum sheets of silica gel 60 F254 using ethyl acetate-methanol-ammonia ( $5: 3: 0.5$ by volume) as mobile phase. Detection was done at $274 \mathrm{~nm}$, and linearity was $0.4-50 \mu \mathrm{g} / \mathrm{band}$ for both drugs [58]. Eissa et al. [59] suggested a TLC densitometric method for the simultaneous detection of brinzolamide and timolol maleate in pharmaceutical products. Separation was carried out with a mobile phase of chloroform to methanol to ammonia (9:0.5:0.1 by volume) on silica gel 60 F254 plates; densitometric analysis was performed at $254 \mathrm{~nm}$ for brinzolamide and $298 \mathrm{~nm}$ for timolol. The linear range was $3-16 \mu \mathrm{g} / \mathrm{spot}$ for brinzolamide and $4-14 \mu \mathrm{g} / \mathrm{spot}$ for timolol maleate [59]. Another HPTLC method was developed by Kulkarni and Amin for analysis of timolol maleate using ethyl acetate to methanol to isopropyl alcohol to ammonia (25\%) (80:20:2:1 by volume) as mobile phase. The calibration curve was linear over a range of 100-600 ng, and the spectro densitometric detection was achieved at $294 \mathrm{~nm}$ [60].

\section{Flumethasone pivalate and/or clioquinol}

\section{1- High-performance liquid chromatography technique (HPLC)}

Hashem [61] developed a HPLC method for the simultaneous quantification of flumethasone pivalate and salicylic acid in bulk and in an ointment dosage form. Separation was achieved on Calixarene stationary phase. The mobile phase was acetonitrile and water $(70: 30 \mathrm{v} / \mathrm{v})$ at a flow rate of $1 \mathrm{~mL} / \mathrm{min}$ at $40^{\circ} \mathrm{C}$. Detection wavelength was $240 \mathrm{~nm}$. Linearity range was $0.5-50 \mu \mathrm{g} / \mathrm{mL}$ [61]. Sayed et al. [62] established an HPLC method for the simultaneous determination of flumethasone pivalate, flumethasone pivalate-related substance and impurity and clioquinol. Separation was achieved within $11 \mathrm{~min}$ using ODS column using acetonitrile-water $(70: 30 \mathrm{v} / \mathrm{v})$ as the mobile phase at a flow rate of $1 \mathrm{~mL} / \mathrm{min}$ with ultraviolet detection was achieved at $235 \mathrm{~nm}$. The calibration plots were linear over the concentration range of 5-50, 2-35, and $10-70 \mathrm{mg} / \mathrm{mL}$, respectively [62]. Chhalotiya et al. [63] introduced a stability indicating RP-HPLC method for the determination of clioquinol in bulk and in pharmaceutical dosage forms. A Sunfire Clgs $4.5 \mu \mathrm{m}$ column with mobile phase of acetonitrile-water $\mathrm{pH} 3(90: 10 \mathrm{v} / \mathrm{v})$ was utilized. The flow rate was $1.0 \mathrm{~L} / \mathrm{min}$, and eluent was monitored at $254 \mathrm{mn}$. Linearity range was $0.1-30 \mathrm{mg} / \mathrm{mL}$ [63]. Lotfy et al. [64] suggested a RP-HPLC method for the simultaneous detection of betamethasone valerate, clioquinol along with their potential interferents including their degradation products, methyl paraben and propyl paraben (preservatives) as well as gentamycin and tolnaftate. Separation was performed on a Zorbax C18 column using water to methanol to acetonitrile to glacial acetic acid
(394:50:550:6, by volume) as a solvent, and the effluents was monitored at $275 \mathrm{~nm}$. The method was linear over the concentration range of $12-240 \mathrm{mg} / \mathrm{mL}, 30-3000 \mathrm{mg} / \mathrm{mL}$, $7-140 \mathrm{mg} / \mathrm{mL}$, and $3.5-70 \mathrm{mg} / \mathrm{mL}$ for betamethasone valerate, clioquinol, methyl paraben, and propyl paraben, respectively [64]. Bondiolotti et al. [65] described an HPLC method for determining clioquinol levels in hamster plasma and tissue. Clioquinol underwent separation on a Nucleosil C18 $300 \mathrm{~mm} \times 3.9 \mathrm{~mm}$ i.d. $7-\mu \mathrm{m}$ column at $1 \mathrm{~mL} / \mathrm{min}$ utilizing a phosphate/citrate buffer $0.1 \mathrm{M}(400 \mathrm{ml})$ with 600 $\mathrm{mL}$ of a methanol to acetonitrile $(1: 1 \mathrm{v} / \mathrm{v})$ as solvent. The method was linear for clioquinol at $5-2000 \mathrm{ng} / \mathrm{mL}$ in plasma and at $10-1000 \mathrm{ng} / \mathrm{g}$ in tissues [65].

\section{2- TLC densitometry}

Sayed et al. [62] developed a TLC-densitometric method for the simultaneous determination of flumethasone pivalate, flumethasone pivalate-related substance and impurity and clioquinol. The proposed TLC-densitometric was performed using silica gel plates 60 F254 as a stationary phase with benzene-hexane-acetone-formic acid (5:4:2:0.13, by volume) as a developing system followed by densitometric measurements at $235 \mathrm{~nm}$. The studied components were quantified in the range of $0.3-4,0.3-3$, and $1.5-5 \mu \mathrm{g} /$ band, respectively [62].

\section{Spectroscopic analysis Brinzolamide and/or timolol maleate}

Salem et al. [58] suggested spectrophotometric and chemometric methods for the simultaneous determination of binary mixture of timolol and travoprost without prior separation in their bulk drugs and dosage forms. The spectrophotometric methods used were derivative spectrophotometry and isosbestic point methods. Multivariate methods involved the application of three chemometric techniques: classical least square (CLS) principal component regression (PCR), and partial least-squares regression (PLS) [58]. Jadhav et al. [66] utilized the spectrophotometric technique for the simultaneous determination of brimonidine tartrate and brinzolamide in bulk and ophthalmic formulation. The absorbance was measured at two wavelengths: $252.40 \mathrm{~nm}$ ( $\lambda$ max of brinzolamide) and $246 \mathrm{~nm}$ ( $\lambda \max$ of brimonidine tartrate) in methyl alcohol. Linearity was $5-35 \mu \mathrm{g} / \mathrm{mL}$ and $3-18 \mu \mathrm{g} /$ $\mathrm{mL}$, respectively [66]. Annapurna et al. [67] suggested two spectrophotometric methods for the simultaneous detection of brimonidine and timolol in ophthalmic solutions using borate buffer. Simultaneous equation method and Q-analysis were used. Linearity was $1-60 \mu \mathrm{g} / \mathrm{mL}$ for timolol and $1-40 \mu \mathrm{g} / \mathrm{mL}$ for brimonidine [67]. Annapurna et al. [67] performed ratio derivative and multicomponent spectrophotometric techniques for the simultaneous detection of brimonidine tartrate and timolol maleate in 
pharmaceutical solutions in borate buffer $\mathrm{pH}$ 9.0. Linearity range was $1-60 \mu \mathrm{g} / \mathrm{mL}$ for timolol maleate and $1-40 \mu \mathrm{g} /$ $\mathrm{mL}$ for brimonidine tartrate [68]. Eissa et al. [69] developed four spectrophotometric methods for the simultaneous detection of brinzolamide and timolol maleate in pharmaceutical formulations. Method A is ratio difference spectrophotometric method (RDSM) that can measure difference in amplitudes between 251 and $265 \mathrm{~nm}$ of ratio spectrum for brinzolamide and between 285 and $306 \mathrm{~nm}$ of ratio spectrum for timolol. Method B is mean centering of ratio spectra method (MCR) by measuring peak amplitude at $252 \mathrm{~nm}$ for brinzolamide and $304 \mathrm{~nm}$ for timolol. Method $\mathrm{C}$ is area under the curve in which the area under the curves for brinzolamide and timolol were selected over the ranges of $260-265 \mathrm{~nm}$ and $282-288 \mathrm{~nm}$. Method D is the bivariate method (BVM), which depends on quantification of absorbances at 265 and $285 \mathrm{~nm}$, respectively. Beer-Lambert's law for the adopted methods were obeyed over the concentration range of $6-36 \mu \mathrm{g} / \mathrm{mL}$ for brinzolamide and 6-42 $\mu \mathrm{g} / \mathrm{mL}$ for timolol [69]. Agrawal et al. [70] suggested a UV spectrophotometric method for the simultaneous determination of brimonidine tartrate and brinzolamide using methanol as a solvent. The $\lambda \max$ for brimonidine tartrate and brinzolamide were found to be $244 \mathrm{~nm}$ and $253 \mathrm{~nm}$, respectively. The linearity was found in the range of $1-7 \mu \mathrm{g} / \mathrm{mL}$ and $5-35 \mu \mathrm{g} / \mathrm{mL}$ for brimonidine tartrate and brinzolamide, respectively [70]. Shah et al. [71] introduced three UV spectroscopic methods named simultaneous equation (method 1$), \mathrm{Q}$-absorbance ratio (method 2 ), and ratio first derivative (method 3 ) for simultaneous detection of brinzolamide and timolol maleate in ophthalmic formulation. Vijya et al. [72] established a spectrophotometric method for the simultaneous detection of brimonidine tartrate as well as brinzolamide in bulk and in pharmaceutical preparations. Such technique involves first-order derivative spectroscopy utilizing 232 $\mathrm{nm}$ and $219.40 \mathrm{~nm}$ as zero crossing points for brimonidine tartrate and brinzolamide, respectively. Methanol was utilized as a solvent. The linearity was $1-7 \mu \mathrm{g} / \mathrm{mL}$ and 5$35 \mu \mathrm{g} / \mathrm{mL}$ for brimonidine tartrate and brinzolamide, respectively [72]. Lotfy et al. [73] developed two spectrophotometric methods (absorbance subtraction as well as amplitude modulation) in order to determine a binary mixture of timolol maleate as well as dorzolamide hydrochloride in the existence of benzalkonium chloride.

\section{Flumethasone pivalate and/or clioquinol}

Abdel-Aleem et al. [74] developed three spectrophotometric methods in order to determine flumethasone pivalate and clioquinol in their binary mixture as well as ear drop solutions. Method A is a ratio subtraction spectrophotometric method (RSM). Method B is a ratio difference spectrophotometric one (RDSM), whereas method $\mathrm{C}$ is the mean center spectrophotometric one
(MCR). The linearity range was $3-45 \mu \mathrm{g} / \mathrm{mL}$ for flumethasone pivalate and $2-25 \mu \mathrm{g} / \mathrm{mL}$ for clioquinol [74]. Nief and Ayad [75] developed spectrophotometric methods for the determination of clioquinol in pharmaceutical formulations and industrial waste water samples. This technique depends on the drug chelation using Fe (III) to produce bluish-green-colored metal chelate at room temperature that absorbs maximally at $639 \mathrm{~nm}$. Beer's law is obeyed over a range of concentration of $2.00-20.00 \mu \mathrm{g} / \mathrm{mL}\left(6.5 \times 10^{-6}\right.$ to $\left.6.5 \times 10^{-5} \mathrm{M}\right)$ [75].

\section{Electrochemical analysis}

Electrochemical methods have the advantages of being simple, fast, and inexpensive with easy sample preparation. Fast thin-layer electrolysis was developed for monitoring the oxidative intermediates of clioquinol in acidic and alkaline media. Two thin-layer electrochemical cells were fabricated and coupled with a UV-visible spectrometer as well as an electrophoresis apparatus, respectively [76]. The voltammetric decrease of flumethasone pivalate was studied using fullerene-C60-modified edge plane pyrolytic graphite electrode (PGE), and the study showed that two well-defined peaks were obtained with a peak potential of $\sim-1220 \mathrm{mV}$ and $\sim-1351 \mathrm{mV}$, respectively, and the linearity was obtained with sensitivity of $0.685 \mu \mathrm{A} \mu \mathrm{M}^{-1}$ and $0.570 \mu \mathrm{A} \mu \mathrm{M}^{-1}$ [77].

\section{Conclusion}

This review investigated the pharmaceutical analysis of four drugs containing heterocyclic ring from 2000 to 2019. These drugs are brinzolamide, timolol maleate, flumethasone pivalate, and clioquinol. The literature review demonstrated various analytical techniques such as chromatographic, spectroscopic, and electrochemical methods that have been employed for the analysis of the aforementioned drugs. The HPLC is the most widely used analytical technique for the analysis of the four selected drugs. Also, the analysis of brinzolamide and timolol maleate is more frequently studied in literature review than flumethasone pivalate and clioquinol (17 studies versus 6 studies, respectively, in chromatographic assay and 8 studies versus 2 studies, respectively, in spectroscopic assay).

\footnotetext{
Abbreviations

TLC: Thin-layer chromatography; HPLC: High-performance liquid chromatography; RP-HPLC: Reversed phase-HPLC; BRZ: Brizolamide; TM: Timolol maleate; FP: Flumethasone pivalate; CL: Clioquinol; LC-MS: Liquid chromatography-mass spectroscopy; LC-GC: Liquid chromatography-gas chromatography; MLC: Micellar liquid chromatographic; UPLC: Ultra performance liquid chromatography; UV: Ultraviolet; CLS: Classical least square; PCR: Principal component regression; PLS: Partial least-squares; RDSM: Ratio difference spectrophotometric method; MCR: Mean centering of ratio spectra method; BVM: Bivariate method; RSM: Ratio subtraction spectrophotometric method; PGE: Pyrolytic graphite electrode
} 


\section{Acknowledgements}

The authors acknowledge Badr University in Egypt and Future University in Egypt for facilitating web review for collecting the required data.

\section{Authors' contributions}

All authors have read and approved the manuscript. N.N. collected all the data and wrote the review. A.M. prepared all figures and participated in writing the review. M.A. revised the methods and references section. H.Z. revised the whole review and updated it.

\section{Funding}

No funding

\section{Availability of data and materials}

Not Applicable (Review Article)

\section{Ethics approval and consent to participate}

Not Applicable

\section{Consent for publication}

Not Applicable

\section{Competing interests}

The authors declare they have no competing interest regarding this review.

\section{Author details}

'Pharmaceutical Chemistry Department, Faculty of Pharmaceutical Sciences and Pharmaceutical Industries, Future University in Egypt (FUE), 90th Street, fifth settlement, New Cairo 11835, Egypt. ${ }^{2}$ Analytical Chemistry Department, Faculty of Pharmacy, Badr University in Cairo (BUC), Entertainment Area, Badr City, Cairo 11829, Egypt. ${ }^{3}$ Analytical Chemistry Department, Faculty of Pharmacy, Cairo University, Kasr El-Aini Street, Cairo 11562, Egypt.

Received: 4 May 2020 Accepted: 30 July 2020

Published online: 12 August 2020

\section{References}

1. Coates J (2006) Interpretation of infrared spectra, a practical Approach. In book: Encyclopedia of Analytical Chemistry. In: Meyers RA (ed) Encyclopedia of Analytical Chemistry. John Wiley \& Sons Ltd, Chichester, pp 10815-10837

2. Gupta M (2015) Heterocyclic compounds and their biological significance: A Review. IJPCMS 4(1):21-24

3. Kumar D, Singh V (2014) Study of heterocyclic compound tetrahydrofuran (THF). IJRST 3:29-32

4. Mossaraf H, Ashis N (2018) A review on heterocyclic: synthesis and their application in medicinal chemistry of imidazole moiety. SJC 6(5):83-94

5. Badgujar JR, More DH, Meshram JS (2018) Synthesis, antimicrobial and antioxidant activity of pyrazole based sulfonamide derivatives. Indian Microbiol 58(1):93-99

6. Molnar M, Pavić V, Šarkanj B, Cacic M, Vukovic D, Klenkar J (2017) Mono-and bis-dipicolinic acid heterocyclic derivatives-thiosemicarbazides, triazoles, oxadiazoles and thiazolidinones as antifungal and antioxidant agents. Heterocycl Commun 23:35-42. https://doi.org/10.1515/hc-2016-007

7. Chitra G, Franklin DS, Sudarsan S, Sakthivel M, Guhanathan S (2017) Indole3-acetic acid/diol-based pH-sensitive biological macromolecule for antibacterial, antifungal and antioxidant applications. Int J Biol Macromol 95: 363-375

8. Wahbi IH, Ishak YC, Khalid A, Adlan T (2014) Inverse virtual screening of some new pyrazolo-[1,5-a]pyrimidine ; 4,6-Dihetarylpyrimidin-2-amine and Ethyl 2-oxo-4,6-di(hetar-2-yl)cyclohex-3-encarboxylate Heterocyclic Compounds From 1,3-Dihetaryl-2-propen-1-one Int. J Pharm Phytopharmacol Res 4 (1): 13-19.

9. Erhan P, Lay GU, Pelin K (2002) Synthesis and anti-inflammatory activity of 1- acylthiosemicarbazides, 1,3,4-oxadiazoles, 1,3,4-thiadiazoles and 1,2,4triazole-3-thiones. Farmaco 57(2):101-107

10. Al-Mulla A (2017) A review: biological importance of heterocyclic compounds. Der Pharma Chemica 9(13):141-147

11. Santos-Sánchez FN, Salas-Coronado R, Villanueva-Cañongo C, HernándezCarlos B (2019) Antioxidant compounds and their antioxidant mechanism, antioxidants. Edited by Emad Shalaby, Intechopen, DOI: https://doi.org/10 5772/intechopen.85270. Available from: https://www.intechopen.com/ books/antioxidants/antioxidant-compounds-and-their-antioxidantmechanism.

12. Chin YW, Balunas MJ, Chai HB, A.D. Kinghorn AD (2006) Drug discovery from natural sources. AAPS J 8(2): 239-253.

13. Putta RR, Donthamsetty VS, Guda RD, Adivireddy P, Venkatapurama P (2017) Synthesis and anti-allergic activity of bis-heteroaryl hydrazines. J. Heterocyclic Chem 54:2216-2222

14. Aboraia SA, Rahman MH, Mahouz MN (2006) Novel 5-(2 hydroxyphenyl)-3substituted-2,3-dihydro-1,3,4-oxadiazole-2-thione derivatives: Promising anticancer agents. Bioorg Med Chem 14:1236-1246

15. Zhao WG, Chen HS, Li ZM, Han YF, Yan H, Lai JY, Wang SH (2001) Synthesis of pyrazolyl-heterocycles and their activities. Chin J Chem 22:939-942

16. Coskun O (2016) Separation techniques: chromatography. North Clin Istanbul 3(2):156-160

17. Patel M (2018) Chromatography principle and applications. IJPPR 13(4):288293

18. Sherma J, Fried B (2003) Handbook of thin-layer chromatography. NEW York, NY

19. Stoddard JM, Nguyen L, Mata-Chavez H, Nguyen K (2007) TLC plates as a convenient platform for solvent-free reactions. Chem Commun (Camb) 12: 1240-1241

20. Al-Rubaye FA, Hameed HI, Kadhim JM (2017) A review: uses of gas chromatography-mass spectrometry (GC-MS) technique for analysis of bioactive natural compounds of some plants. IJPTR 9(1):81-85

21. Regnier FE (1983) High performance liquid chromatography of biopolymers. Science 222(4621):245-252

22. Lotfy MH, Saleh S (2016) Recent development in ultraviolet spectrophotometry through the last decade (2006-2016): A REVIEW. Int J Pharm Pharm Sci 8(10):40-56

23. Roggo Y, Chalus P, Maurer L, Lema-Martinez C, Edmond A, Jent N (2007) A review of near infrared spectroscopy and chemometrics in pharmaceutical technologies. J Pharm Biomed Anal 44(3):683-700

24. De Beer T, Burggraeve A, Fonteyne M, Saerens L, Remon J.P, Vervaet C (2011) Near infrared and Raman spectroscopy for the in-process monitoring of pharmaceutical production processes. Int J Pharm 417(1-2):32- 47

25. Harvey D (2000) Text book of modern analytical chemistry, 1st Edition, DePAUW University, International Edition, McGraw-Hill Companies. pp 476477.

26. Cuppo FLS, Gomez SL, Figueiredo Neto AM (2004) Effect of the concentration of magnetic grains on the linear-optical-absorption coefficient of ferrofluid-doped lyotropic mesophases: deviation from the Beer-Lambert law. Eur Phys J E 13(4):327-333

27. Andrews DL (2014). Molecular photophysics and spectroscopy. UK: Morgan and Claypool Publishers:1-1 to 1-3. Doi: https://doi.org/10.1088/978-1-62705288-7ch1.

28. Kamal AH, El-Malla SF, Hammad SF (2016) A review on UV spectrophotometric methods for simultaneous multicomponent analysis. EJPMR. 3(2):348-360

29. Redasani VK, Patel PR, Marathe Dy, Chaudhari SR, Shirkhedar AA, Surana SJ (2018). A review of derivative UV spectrophotometry analysis of drugs in pharmaceutical formulations and biological samples review. JCCHEMS, Vol 63, no.3, On-line ISSN 0717-9707

30. Labib M, Sargent E, Kelley S (2016) Electrochemical methods for the analysis of clinically relevant biomolecules. Chem Rev 116(16):9001-9090

31. Eggins BR (2002) Chemical sensors and biosensors. John Wiley \& Sons, England

32. Ronkainen NJ, Halsall HB, Heineman WR (2010) Electrochemical biosensors. Chem Soc Rev 39:1747-1763

33. Matsumoto A, Miyahara $Y$ (2013) Current and emerging challenges of field effect transistor-based bio-sensing. Nanoscale 5:10702-10718

34. Pub Med. https://pubchem.ncbi.nlm.nih.gov/compound/brinzolamide

35. Drug monograph. https://www.drugs.com/monograph/brinzolamide.html

36. Drug bank. https://www.drugbank.ca/drugs/DB01194

37. Pub Med. https://pubchem.ncbi.nlm.nih.gov/compound/Timolol-maleate

38. Drug monograph. https://www.drugs.com/monograph/timolol-maleate.html

39. Drug bank. https://www.drugbank.ca/salts/DBSALT000989

40. Pub Med. https://pubchem.ncbi.n/m.nih.gov/compound/Flumethasonepivalate

41. Drug bank. https://www.drugbank.ca/salts/DBSALT001004

42. Pub Med. https://pubchem.ncbi.nlm.nih.gov/compound/clioquinol

43. Drug bank. https://www.drugbank.ca/drugs/DB04815 
44. Ibrahim FA, Elmansi HM, Abass SA (2019) A versatile HPLC method with an isocratic single mobile phase system for simultaneous determination of anti-glaucoma formulations containing timolol. Ann Pharmacother 77(4): 302-312

45. Patel P, Darji VC, Patel BR (2019) Analytical method development and validation of stability indicating RP-HPLC method for estimation of brinzolamide and brimonidine tartrate in an ophthalmic suspension. IJRAR: 6 I: 150-156.

46. Anusha B, Susmita AG, Rajitha G (2016) Analytical method development and validation of new RP-HPLC method for simultaneous estimation of brinzolamide and timolol Maleate in ophthalmic solutions. Res J Pharm Boil Chem Sci 7(3):1290-1298

47. Shankar CH, Venkateshwarlu P (2016) Analytical method development and validation for the simultaneous estimation of brinzolamide and timolol maleate by RP-HPLC method in bulk and tablet dosage form. Int J Curnt Tren Pharm, Res 4(2):84-90

48. Hassib ST, Elkady EF, Sayed RM (2016) Simultaneous determination of timolol maleate in combination with some other anti-glaucoma drugs in rabbit aqueous humor by high performance liquid chromatographytandem mass spectroscopy. J Chromatogr B Anal Technol Biomed Life Sci 1(1022):109-117

49. Agrawal VP, Desai SS, Jani JK (2016) Development of RP-HPLC method for simultaneous determination of brimonidine tartrate and brinzolamide by QbD Approach and Its Validation. Eurasian J Anal Chem 11(2):63-78

50. Christian JR, Patel K, Gandhi TR (2016) Validation and experimental design assisted robustness testing of RPLC method for the simultaneous analysis of brinzolamide and brimonidine Tartrate in an ophthalmic dosage form. Indian J Pharm Sci 78(5):631-640

51. Kumari VR, Venkateswarrao P, Sunitha A, Keerthy K (2015) Stability indicating RP-HPLC method for simultaneous estimation of travopost and timolol in bulk and pharmaceutical dosage forms. IJPRR 5(3):176-182

52. Rizk MS, Merey HA, Tawakkol SM, Sweilam MN (2015) Development and validation of a stability-indicating micellar liquid chromatographic method for the determination of timolol maleate in the presence of its degradation products. J Chromatogr Sci 53(4):503-510

53. Hafez MH, Elshanawany AA, Mohram SM (2015) Design of experiment utilization to develop a simple and robust RP-UPLC method for stability indicating method of anti- glaucoma ophthalmic drops. Eurasian J Anal Chem 10(1):46-67

54. Khatun R, Islam A (2014) Development and validation of analytical method for simultaneous estimation of brinzolamide and timolol by HPLC from ophthalmic preparation. IJPSR 5(3):1001-1007

55. Laddha UD, Barse RK, Zilpelwar RV, Amol T (2014) Development and validation of stability indicating reverse phase high performance liquid chromatography method for timolol maleate. Int.J. PharmTech Res 6:14291435

56. Elshanawane AA, Abdelaziz ML, Mohram SM, Hafez MH (2014) Development and validation of HPLC method for simultaneous estimation of brimonidine tartrate and timolol maleate in bulk and pharmaceutical dosage form. J Chromatograph Separat Techniq 5(3):1-5

57. Sharma N, Rao SS, Reddy AM (2012) A novel and rapid validated stabilityindicating UPLC method of related substances for dorzolamide hydrochloride and timolol maleate in ophthalmic dosage form. J Chromatogr Sci 50(9):745-755

58. Salem H, Aboulkheir A, AbdelAziz EB (2019) Development and validation of novel spectro-chemometric, chemometric and TLC-densitometric methods for simultaneous determination of timolol and travoprost in their bulk powders and pharmaceutical formulation. APPR 2(1):1-11

59. Eissa MS, Nour MI, Elghobashy RM, Shehata MA (2018) Validated TLCdensitometry method for simultanouse determination of brinzolamide and timolol in their ophthalmic preparation. Analytical Chemistry Letters 7(6): 805-812

60. Kulkarni SP, Amin PD (2000) Stability indicating HPTLC determination of timolol maleate as bulk drug and in pharmaceutical preparations. J Pharm Biomed Anal 23(6):983-987

61. Hashem H (2016) Chromatographic application on a calixarene stationary phase: a novel HPLC determination of flumethasone pivalate and salicylic acid in their binary mixture and ointment dosage form after two steps extraction. UKJPB 4(2):70-76

62. Sayed NW, Hegazy MA, Abdel-Aleem EA, Abdelkawy M, Abdelfatah RM (2014) Two validated liquid chromatographic methods for the simultaneous determination of flumethasone pivalate, its related substance (flumethasone), and Clioquinol. JPC 27(6):466-471

63. Chhalotiya UK, Bhatt KK, Shah AD, Baldania SL, Patel MR (2014) Quantification of clioquinol in bulk and pharmaceutical dosage forms by stability indicating LC method. Turk J Pharm Sci 11:67-78

64. Lotfy MH, Abdel-Moety EM, Nouman EG (2014) Selective liquid chromatographic quantification of betamethasone valerate and clioquino in presence of potential interferents. Int J Pharm Pharm Sci 6(7):79-85

65. Bondiolotti GP, Pollera C, Pirola R, Bareggi SR (2006) Determination of 5chloro-7-iodo-8-quinolinol (clioquinol) in plasma and tissues of hamsters by high-performance liquid chromatography and electrochemical detection. J Chromatogr B Anal Technol Biomed Life Sci 837(1-2):87-91

66. Jadhav VL, Patil AS, Chaudhari RS, Shirkhedkar AA (2019) UVSpectrophotometry - multicomponent mode of analysis for simultaneous estimation of brinzolamide and brimonidine tartrate in bulk and ophthalmic formulation. JPTRM 7(1):31-35

67. Annapurna MM, Sushmitha M, Sevyatha V, Narendra A (2017) New spectrophotometric methods for the simultaneous determination of brimonidine and timolol in eye drops. JCHPS 10(2):786-789

68. Annapurna MM, Sushmitha M, Sevyatha V (2017) Simultaneous determination of brimonidine tartrate and timolol maleate by first derivative and ratio derivative spectroscopy. J Anal Pharm Res 4(6):00120. https://doi. org/10.15406/japlr.04.00120

69. Eissa MS, Nour MI, Elghobashy RM, Shehata MA (2016) Validated spectrophotometric methods for simultaneous determination of brinzolamide and timolol maleate in their pure form and ophthalmic preparation. Az J Pharm Sci 54:188-202

70. Agrawal VP, Desai SS, Jani GK (2015) Development of ultraviolet spectrophotometric method for the simultaneous estimation of brimonidine tartrate and brinzolamide. Indian Drugs 52(11):29-34

71. Shah AU, Kadikar SA, Katira MR, Kalpana G, Gandh TP (2014) Simultaneous determination of brinzolamide and timolol maleate using three different spectrophotometric methods. WJPPS 3(2):1955-1967

72. Vijya A, Patel JD, Meshram BD (2014) Development and validation of derivative spectrophotometric method for simultaneous estimation of brimonidine tartrate and brinzolamide in combined dosage form. IAJPS 4(3): $1472-1478$

73. Lotfy HM, Hegazy MA, Rezk MR, Omran YR (2014) Novel spectrophotometric methods for simultaneous determination of timolol and dorzolamide in their binary mixture. Spectrochim Acta A Mol Biomol Spectrosc 126(21): 197-207

74. Abdel-Aleem EA, Hegazy MA, Sayed NW, Abdelkawy M, Abdelfatah RM (2015) Novel spectrophotometric determination of flumethasone pivalate and clioquinol in their binary mixture and pharmaceutical formulation. Spectrochim Acta A Mol Biomol Spectrosc 136 (5) Pt B:707-713.

75. Nief R, Ayad A (2013) Spectrophotometric determination of clioquinol via complex formation with Fe (III) in pharmaceutical preparations (creams) and environmental wastewater samples. Kerbala Journal of Pharmaceutical Sciences 5: 91-9

76. Wen WZ, Lin LX, Ning D, Yan W, Jian-Bo H (2014) Monitoring of intermediates of clioquinol electro-oxidation by thin-layer spectral and electrophoretic electrochemistry. Electrochim Acta 127:403-409

77. Goyal RN, Chatterjee S, Bishnoi S (2009) Sensitive voltammetric sensor for determination of flumethasone pivalate, abused for doping by athletes. Sensors Actuators B Chem 137(2):676-680

\section{Publisher's Note}

Springer Nature remains neutral with regard to jurisdictional claims in published maps and institutional affiliations. 